eISSN: 2659-6482

DOI: https://doi.org/10.14201/pmrt.19019

\title{
EL ORFEÓ CATALÀ Y SUS CONCIERTOS PARISINOS DE 1914: DE LA ESTELA DE UNA DIVA AL TRIUNFO DE LO POPULAR
}

\section{The Orfeó Català and its Parisian concerts of 1914: from the wake of a diva to a the triumph of popular music}

\author{
Virginia SÁNCHEZ RODRÍGUEZ \\ Universidad de Castilla-La Mancha \\ virginia.sanchez@uclm.es
}

RESUMEN: En este trabajo ofrecemos un acercamiento al viaje que el Orfeó Català realizó a París, como parte de la excursión artística a París y Londres en junio de 1914. A través del acceso a fuentes primarias y fuentes hemerográficas españolas y francesas, recuperaremos los acontecimientos que rodearon el periplo y conoceremos cómo fue la recepción por parte del público y de la prensa. Asimismo, y a pesar de que la publicidad previa al evento utilizaba la figura de María Barrientos - la soprano española más célebre del momento - como aval al Orfeó en el viaje, en este trabajo trataremos de demostrar que la agrupación barcelonesa logró brillar con luz propia a través de su calidad técnica y de la vistosidad del repertorio popular.

Palabras clave: Orfeó Català; Lluís Millet; María Barrientos; París; prensa.

ABSTRACT: In this work we offer an approach to the journey that the Orfeó Català made to Paris, as a part of the artistic excursion to Paris and London in June 1914. Throughout primary sources and Spanish and French newspaper sources, we will recover the events that surrounded the tour and we will know how was the reception by the public and the press. Also, and despite the fact that the publicity prior to the event used the figure of María Barrientos - the most famous Spanish soprano of the moment-, as patroness of the Orfeó in the journey, in this work we will try 
VIRGINIA SÁNCHEZ RODRÍGUEZ

EL ORFEÓ CATALÀ Y SUS CONCIERTOS PARISINOS DE 1914: DE LA ESTELA

DE UNA DIVA AL TRIUNFO DE LO POPULAR

to demonstrate that the Barcelona group succeeded thanks to its technical quality and the brilliance of the popular repertoire.

Keywords: Orfeó Català; Lluís Millet; María Barrientos; Paris; press.

\section{INTRODUCCIÓN}

Lo popular y lo culto han sido dos realidades que han convivido, de forma cohesionada y armónica, en cada época de la historia. Y es que, a pesar de que la historiografía ha ponderado los testimonios cultos por encima de las manifestaciones populares, ambas tendencias han sido, son y serán un ente unitario en el existir cotidiano. Eso mismo ha sucedido en el contexto musical, donde los límites entre lo popular y lo culto siempre han sido muy difusos ${ }^{1}$. De hecho, en el siglo XIX, denominado «el siglo de los nacionalismos» ${ }^{2}$, la música popular comenzó a cobrar un gran protagonismo dentro de la escritura musical y literaria de los músicos, a pesar de que, en algunas ocasiones,

el folklore utilizado como base musical durante el siglo XIX distaba considerablemente de la fidelidad de las tradiciones vivas. Estilizado y regularizado por las clases burguesas, la toma de la música tradicional no distaba en exceso de las apropiaciones exóticas de músicas foráneas o de la repetición de una serie de tópicos susceptibles de utilización política ${ }^{3}$.

Más allá de la autenticidad del material, lo cierto es que, especialmente durante las últimas décadas del siglo XIX y el primer tercio del siglo XX, las músicas de carácter tradicional experimentaron un creciente interés. En esos momentos no solo comenzaron a proliferar los trabajos de campo por parte de musicólogos y

1. A lo largo de la historia de la música, han sido muchos los compositores que se han inspirado en las melodías procedentes del ámbito popular para formar parte de obras cultas. Tal es el caso de la canción L’homme armé, que sirvió como cantus firmus para misa latina en más de cuarenta composiciones sacras ya desde el Renacimiento, o, situándonos en el contexto hispano de la misma época, de la armonización polifónica de poemas populares que fueron integrados en el Cancionero Musical de Palacio y que forman parte hasta la actualidad del repertorio vocal más culto e histórico. Vid. Sánchez Rodríguez, Virginia (2014). «La dignificación de lo popular en la música renacentista», ArtyHum: revista digital de artes y bumanidades, 3, pp. 119-211. Disponible en: <https://www.artyhum.com/> [Ultima consulta: 11 de junio de 2018].

2. Romeo Mateo, María Cruz; Saz, Ismael (coords.) (2002). El siglo XX. Historiografía e historia, p. 9, Valencia: Universitat de València.

3. Sánchez Rodríguez, Virginia (2017). «Nacionalismo y universalismo en torno al pensamiento musical de Manuel de Falla», ArtyHum: revista digital de artes y bumanidades, 38, p. 125. Disponible en: <https://www.artyhum.com/> [Última consulta: 11 de junio de 2018]. 
VIRGINIA SÁNCHEZ RODRÍGUEZ

EL ORFEÓ CATALÀ Y SUS CONCIERTOS PARISINOS DE 1914: DE LA ESTELA

DE UNA DIVA AL TRIUNFO DE LO POPULAR

etnomusicólogos - con la intención de anotar, preservar y transmitir las melodías tradicionales de carácter oral y evitar, de este modo, su pérdida-, sino que, especialmente durante el Nacionalismo - aunque no de forma exclusiva en torno a esta corriente estética-, los compositores de música académica o culta comenzaron a valorar las melodías tradicionales como fuente de inspiración y como material musical.

Véase al respecto, de acuerdo con el contexto cronológico y geográfico del presente trabajo, la labor Felipe Pedrell (1841-1922). Considerado el padre del nacionalismo musical hispano ${ }^{4}$ y renovador de la música en torno a diferentes vertientes ${ }^{5}$, en lo relativo al contexto popular cabe destacar que Pedrell persiguió la forma más prístina del folklore con la intención de dotar a las melodías tradicionales de un soporte material para que no desaparecieran y de que el canto popular formara parte de otras manifestaciones del contexto culto, como la ópera nacional. Este aspecto es algo en lo que el propio Pedrell coincide también con Francisco Asenjo Barbieri (1823-1894). Ambos personajes no solo presentan nexos en su mentalidad y en su labor 6 , sino que son considerados defensores de la visibilidad de la función del canto popular en una realidad en la que lo popular y lo culto no parece tan lejano, entre otras contribuciones. Véase al respecto el testimonio de Emilio Casares Rodicio en «Pedrell, Barbieri y la restauración musical española»:

Es más, incluso cuando hablamos de la recuperación del canto popular estricto éste es un valor real que hay que colocar al menos en la ideología de Pedrell y Barbieri con el mismo sentido del amor al paisaje en la generación del 98. Diríamos que todo nacionalismo implica una selección y una serie de amnesias y éstas están claras en

4. «Quan hom parla de Pedrell, la primera idea que sorgeix és sempre la del capdavanter del nacionalisme musical al nostre país. Nombrosos textos del compositor i musicòleg, com també diverses aportacions dels seus deixebles i, finalment, dels estudiosos d'aquest moviment cultural, han convingut a atorgar-li el protagonisme indiscutible en aquest tema». Bonastre, Francesc (1991-1992). «El nacionalisme musical de Felip Pedrell. Reflexions a l'entorn de Por nuestra música...», Recerca Musicològica, XI-XII, p. 17.

5. Para una mayor profundización, vid. Gregori, Josep Maria (1991-1992). «Felip Pedrell i el renaixement musical hispànic», Recerca Musicològica, XI-XII, pp. 47-61.

6. «Barbieri y Pedrell, más allá de la trascendencia de su obra, tanto musical como musicológica, suponen el intento más decidido y consciente de llevar a cabo esta restauración y entre los dos se establece una relación de continuidad ideológica y estética, representantes como eran de dos generaciones distintas y contiguas, los separaban dieciocho años de edad. Esta tesis es plenamente demostrable en sus cartas, en las que se exponen los asuntos claves de esta restauración: El rescate del pasado histórico y sus figuras, las investigaciones y catalogaciones en las catedrales, los estudios de organología, el nacimiento del teatro lírico nacional, el ataque a la incultura de los músicos, la idea nacionalista. Estos son temas que preocupan a ambos y sobre los que no solo tienen ideas sino actuaciones comunes». Casares, Emilio (1991-1992). «Pedrell, Barbieri y la restauración musical española», Recerca Muscològica, XI-XII, p. 262. 
ambos. Es decir, la restauración del canto popular es una idea menos epidérmica y más profunda de lo que se ha dicho. Pedrell señala la salida en la búsqueda «de la filiación en la tradición no interrumpida de ese pasado que enterró la ignorancia y ha dejado perder el olvido más vergonzoso y deplorable en que pueda incurrir una nación». Y en la precisión de en qué consiste el beber en el canto popular, siempre une este canto con los términos de lo culto: «De ese feliz consorcio entre el tema popular y culto nace no solo el color local, sino también el de la época que se compenetran en la obra del compositor» ${ }^{7}$.

Esta simbiosis entre lo popular y lo culto, latente en la sociedad del momento, es la que también rodeó la labor performativa de la soprano española María Barrientos (1884-1946). A pesar de que la diva gozaba ya de gran éxito y prestigio a comienzos del siglo XX, y aunque fue considerada una de las grandes sopranos de coloratura del momento, a lo largo de su vida siempre mostró una gran vinculación al repertorio de carácter tradicional y a algunas instituciones vinculadas con el contexto popular. Tal es el caso de su colaboración con el Orfeó Català, junto con el que participó en una gira por las ciudades de París y Londres en el año 1914 con la intención de mostrar al mundo la excelencia de la agrupación coral y las virtudes del repertorio de tintes populares. Dado que la relación entre lo popular y lo culto, por motivos que desentrañaremos más adelante, tuvo un significado especial en la primera parada del viaje, en el presente trabajo nos centraremos en el estudio de los conciertos ofrecidos por el Orfeó Català en la Ciudad de París en junio de 1914. ¿Cómo se desarrolló el viaje en el caso de una agrupación de tales dimensiones? ¿Qué pudo alterar el repertorio musical inicialmente programado, con la participación de la Barrientos, en favor de una mayor incidencia tradicional? ¿Cómo fue la acogida de un repertorio mayoritariamente localista, especialmente vinculado a la región de Cataluña, por parte del público y de la crítica franceses?

\section{EL ORFEÓ CATALÀ: UNA INSTITUCIÓN NACIDA PARA LA GLORIFICACIÓN Y DIFUSIÓN DEL REPERTORIO TRADICIONAL DE CATALUÑA}

Fundado el 6 de septiembre de $1891^{8}$ por Lluís Millet (1867-1941) y Amadeo Vives (1871-1932), desde su origen el Orfeó Català se caracterizó por la glorificación del repertorio tradicional de la región de Cataluña, por su calidad musical y por haberse rodeado de grandes artistas. Aunque su primera actuación en público

7. Ibid., p. 271.

8. Millet i Loras, Lluís (2004-2005). «El llegat històric de l'Orfeó Català (1891-1936)», Recerca Musicològica, XIV-XV, p. 141. 


\section{VIRGINIA SÁNCHEZ RODRÍGUEZ \\ EL ORFEÓ CATALÀ Y SUS CONCIERTOS PARISINOS DE 1914: DE LA ESTELA \\ DE UNA DIVA AL TRIUNFO DE LO POPULAR}

tuvo lugar el 5 de abril de 1892, con un repertorio interpretado exclusivamente por voces masculinas, en 1896 ya se integraron voces femeninas e infantiles, dando lugar a su composición actual9.

Una de las finalidades del Orfeó Català ${ }^{10}$, que estuvo dirigido por Lluís Millet hasta su fallecimiento, era, además de crear una agrupación capaz de interpretar la música universal más paradigmática, la de divulgar las canciones tradicionales catalanas. En concreto, según el acta fundacional, del que se hace eco Lluís Millet i Loras en «El llegat històric de l'Orfeó Català (1891-1936)», la agrupación nació:

«per a l'únic i exclusiu fi de fomentar la música catalana, i encara alguna altra que no ho sigui, sempre que es refereixi a fer conèixer belleses artístiques que tinguin relació directa amb la nostra...». Inicialment format per 28 cantaires masculins, aquests efectius foren ampliats amb una secció de nois, el 1895, i una «secció de senyoretes», el $1896^{11}$.

En ese sentido, y con la voluntad divulgadora a la que acabamos de hacer referencia, la institución no solo se interesó en recopilar y entonar melodías del imaginario catalán, sino que también comenzó a interpretar diversas adaptaciones para coro del repertorio de carácter oral. Para ello, el Orfeó se nutrió de armonizaciones de melodías de carácter tradicional, algunas de ellas elaboradas por grandes músicos y musicólogos. De este modo, una vez más, la línea entre lo popular y lo culto quedaba difuminada en el instante en que un músico, a través de las reglas propias del paradigma tonal, trabajaba sobre una melodía del imaginario colectivo a la que dotaba de diversas voces. Un ejemplo ilustrativo de las armonizaciones a las que acabamos de hacer referencia lo representa el célebre «El cants dels ocells», testimonio popular catalán que gozó de varias armonizaciones para coro del propio director, Lluís Millet, de Jaume Pahissa (1880-1969) y de Kurt Schindler (1882-1935).

9. Página web del Orfeó Català. Disponible en: $<$ http://www.orfeocatala.cat/es $>$ [Última consulta: 25 de junio de 2018].

10. Para una mayor profundización sobre la historia del Orfeó Catalá, Vid. Narváez Ferri, Manuela (2005). L'Orfeó Català, cant coral i catalanisme (1891-1951) (tesis doctoral), Barcelona: Universitat de Barcelona; Roig Rosich, Josep Maria (1993). L'Orfeó Català. Moments cabdals del seu passat, Barcelona: Publicacions de l'Abadia de Montserrat; Millet i Loras, Lluís (2004-2005). «El llegat històric de l'Orfeó Català (1891-1936)», Recerca Musicològica, XIV-XV, pp. 139-153.

11. Millet i Loras, Lluís. «El llegat històric de l'Orfeó Català...», Op. cit., p. 141. 
VIRGINIA SÁNCHEZ RODRÍGUEZ

EL ORFEÓ CATALÀ Y SUS CONCIERTOS PARISINOS DE 1914: DE LA ESTELA DE UNA DIVA AL TRIUNFO DE LO POPULAR

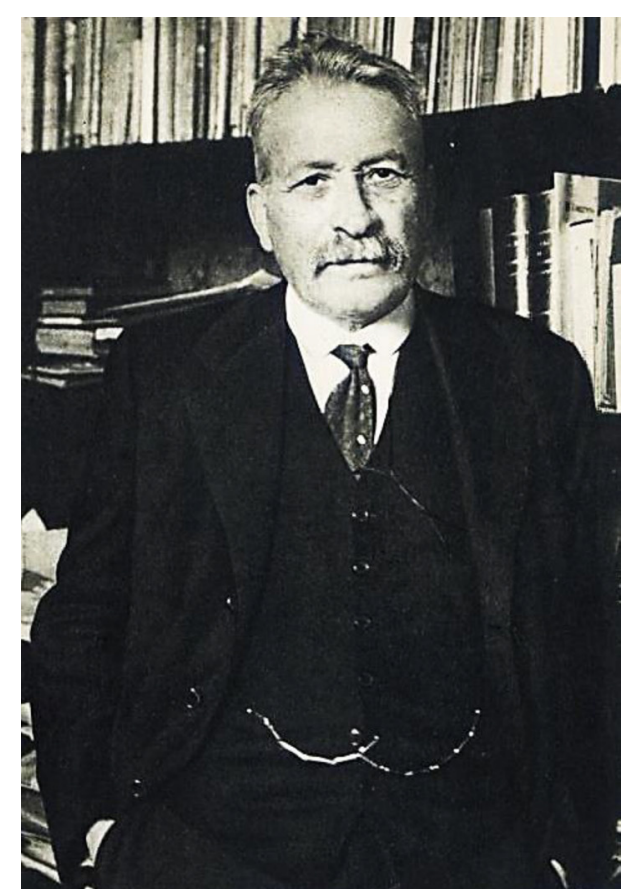

Fotografía 1. Lluís Millet (1867-1941). Fuente: Archivo Sánchez Rodríguez

A este respecto, en ocasiones, era el propio Lluís Millet quien solicitaba la colaboración a grandes músicos para la armonización de melodías de carácter popular, como se puede constatar en una carta enviada a Pedrell el día 2 de septiembre de 1896, de la que se hace eco M. Dolors Millet i Loras en su artículo «Lluís Millet a Felip Pedrel -Epistolari-», en la que le solicita la armonización de alguna canción popular:

Ara vull demanar-li un altre favor i vagi sumant. Com vostè sap, l'Orfeó va néixer principalment per a cooperar al renaixement del cant popular català; per això no hem descuidat mai el conreu de nostra cançó. Aquest any sobretot pensó eixamplar el posible el repertori del gènere: ara bé, si $\mathrm{V}$. ens fes la caritat d'harmonitzar-nos algún d'aquells cants de nostra terra que té guardat amb tant d'amor, el nostre agraïment fóra etern. Ho farà? ${ }^{12}$

12. Millet i Loras, M. Dolors (1986-1987). «Lluís Millet a Felipe Pedrell -Epistolari-», Recerca Musicològica, VI-VII, p. 265.

Ediciones Universidad de Salamanca /

묘

Popular Music Research Today, pp. 121-154 
No sorprende la confianza, no ajena de un gran respeto, a la hora de llevar a cabo esta petición ya que Millet fue discípulo de Pedrell. Finalmente, Pedrell accedió a la petición y aportó la escritura a varias voces mixtas de un «Goigs» (Gozo), tal como se indica en una carta de 21 de septiembre de 1896 de Lluís Millet al músico catalán a la que, nuevamente, Millet i Loras hace referencia ${ }^{13}$. Más allá de lo anecdótico de este hecho, desde una perspectiva global, esta forma de proceder denota la valoración del repertorio popular y la voluntad de difusión del mismo a través de una agrupación pionera como el Orfeó. En todo caso, en el contexto musical de la época era conocida la valoración de las melodías tradicionales por parte de Millet y bien destacada la labor que estaba desempeñando. Véase al respecto la mención a Lluís Millet por parte del compositor y musicólogo valenciano Eduardo López-Chávarri (1871-1970), gran conocedor e interesado en la recopilación y preservación de la música tradicional, en Música Popular Española (1927):

Otro artista de raza, Luis Millet, ha comprendido que «la esencia del canto popular consiste en la ingenuidad y en la plenitud, dentro de las más sencillas formas. Es gracia pregonada por la emoción viva, por la exaltada imaginación, como todo arte al que vivifica belleza; pero el canto del pueblo, por falta de refinamiento educativo, tiene una expresión más directa de la emoción estética. El pueblo es crédulo y sencillo ante las maravillas del mundo; el pueblo es niño... Y en el pueblo todo tiene un sentido más gracioso, una virginidad más pura, una inocencia que sobrepasa a toda sabiduría» (de La Cançó Popular Catalana. Bloud y Gay, editores, Barcelona) ${ }^{14}$

Por tanto, y retomando el enfoque del presente trabajo, podemos afirmar que las armonizaciones, junto con la interpretación de obras culmen de la historia de la música en el contexto culto, contribuyeron, desde su origen, en el diseño del repertorio del Orfeó Català. Así, junto con las grandes obras de la historia de la música, la interpretación de melodías tradicionales para voces mixtas se convirtió en una de las señas de identidad de la agrupación, también patente en la temporada 1913-1914 en que el Orfeó realizó una gira por Francia y Reino Unido acompañado por algunos de los artistas españoles, de origen catalán, más célebres y aclamados del momento.

Además del trabajo de formación musical con los aficionados que se interesaban en formar parte de la agrupación coral, y junto con los alumnos de la escuela de música infantil dependiente del mismo, el Orfeó Català solía realizar actuaciones en colaboración con grandes músicos profesionales de la región. De ese modo, el

13. Ibid., p. 265.

14. López-Chávarri, Eduardo (1940). Música Popular Española (1ª edición, 1927), Madrid: Labor, pp. 9-10. 
hecho no solo suponía publicidad para el orfeón, aprovechando el nombre de los artistas, sino que se dotaba de un aura un tanto más culto al repertorio interpretado.

A este respecto, en junio de 1914 el Orfeó Català, encabezado por Lluís Millet, viajó a las ciudades de Londres y París para ofrecer varios conciertos. Los más de doscientos cincuenta componentes, además de interpretar un repertorio coral, fueron acompañados por la soprano María Barrientos, el violinista Joan Manén (1883-1971) y el pianista Blai Net (1887-1948). Los tres músicos, de origen catalán, eran representantes de una misma generación, eran abanderados de una calidad musical sin par y participaron de igual manera como parte del programa musical que se interpretó en ambas ciudades europeas. De todos ellos, María Barrientos fue la artista que contaba con mayor fama internacional en el momento y que gozaba con el favor de la prensa, lo que parece constatado a través de la publicidad previa a los conciertos. Sin embargo, tal como señalaremos a continuación, se produjo una circunstancia que impidió la participación de la diva en París pero que no enturbió las interpretaciones de la sociedad coral catalana.

\section{LA GIRA DEL ORFEÓ CATALÀ EN PARÍS Y SU RECEPCIÓN}

Las actuaciones musicales en suelo francés y británico previstas en junio de 1914 eran todo un reto para los directivos del Orfeó Català, pues significaba la exportación al mundo de la excelsa labor que estaban realizando en Cataluña. Por ello, el director y los artistas profesionales invitados se volcaron de lleno en el proyecto, así como los socios benefactores de la institución y los organismos que habitualmente colaboraban, como el Ayuntamiento y la Diputación. Aunque para Millet, Barrientos, Manén y Blai se trataba de un viaje de trabajo, a los componentes de la agrupación coral se les presentó como una «excursión artística». Así consta en el libro que el Orfeó editó con las normas de convivencia y con una serie de recomendaciones para el viaje, un plan sumamente atractivo para los cantantes del orfeón que no se vio exento de la responsabilidad que significaba ser embajador musical de la labor de la institución en Europa.

En relación con la naturaleza de este viaje, y de acuerdo con el entusiasmo y el esmero en su preparación, véanse al respecto las palabras de Lluís Millet al comienzo del citado libreto:

Estimats cantaires de l'Orfeó Català:

L'excursió artística que anem a realizar a París y a Londres té una importancia suprema per a la nostra entitat estimada. Quasi bé podem asegurar que és l'esforç més extremat que havem realitzat, deixant apart el culminant fet per bastir el nostre Palau de la Música Catalana. Comptant solamente amb nostres propies forces no haguérem pas arribat a portar a terme els nostres desitjos de que el món artístic de 
les dues més grans capitals d'Europa, sancionés la nostra obra que tants fatigs ens costa i que, també, tantes satisfaccions ens ha donat en recompensa.

Penseu que sense l'ajuda inicial i inapreciable de l'eximia María Barrientos; sense la generositat de nostre Excel-lentísim Ajuntament i de la nostra Diputació, protectora sempre nostra; sense tantes personalitats que ens estimen i que ho demostren responent del déficit qasi segur de nostra excursió; sense aquest escalf dels nostres socis protectors, que ens anima i ens dóna conciencia de lo què representem dins la Catalunya mare nostra; penseu que sense tota ix`que ens empeny i ens porta a la ventura per aixecar el nom de la Patria, no haguérem pogut realizar nostre somni; penseu-ho, mediteu-ho i sentireu tota la forta responsabilitat que pesa sobre nosaltres.

Cal, doncs, que us feu càrrec tots de com deveu cooperar al bon èxit de nostra gran excursió. Primerament heu de pensar que sereu com soldats d'un exèrcit de la Patria que va a proclamar en el gran món civilitzat la nostra cultura artística; que com a tals soldats heu de guardar la més extrema disciplina. No anem a passejar, anem a treballar; i anem a treballar en una feina de cos i ànima. Per a cantar bé es necesita descans del cos i serenitat d'esperit. Si us canseu anant d'un lloc a l'altre, amb l'afany de veure-ho tot; si els homes fan abús de begudes i de fumar; si les senyoretes no reprimeixen el garlar continuament; si tots plegats vos deixeu portar pel rodament de cap, per la girada de cervell que sol encomanar-se als novells visitados de les grans ciutats mondials que anem a visitar; si tothom no té molt enteniment, ens exposem, am seguretat, al fracàs de nostre èxit artístic $i$ al menyspreu de tota la gent de dins i fòra de casa que tindrà els ulls sobre nosaltres.

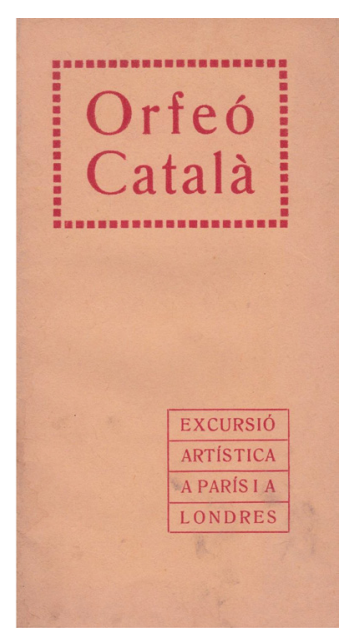

Figura 1. Libreto entregado a los componentes del Orfeó Català participantes en el viaje, portada. Fuente: Archivo Sánchez Rodríguez 


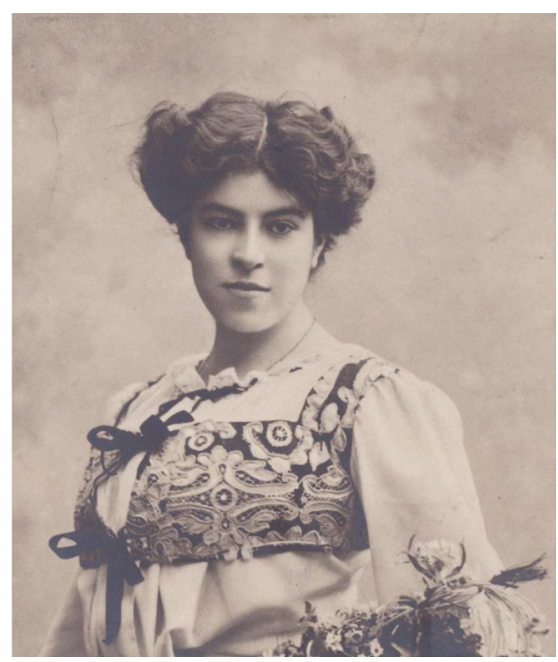

Fotografía 2. María Barrientos (1884-1946). Fuente: Archivo Sánchez Rodríguez

Heu de penser que no és un concert lo que anem a fer, sinó una tanda de manifestacions artístiques solemnes, que, de la primera a la última, cal que surtin amb tota la perfecció posible. Famosos Mestres extrangers ens han alabat per haver-nos sentit a casa nostra; d'aquestes lloances nosaltres n’hem fet us ara públicament. ¡Quína vergonya fóra, doncs, que la nostra tasca no correspongués a lo que aquests grans Mestres han dit de nosaltres! $!^{15}$.

Como se puede comprobar, específicamente Millet dedica unas palabras de agradecimiento a María Barrientos por su ayuda, lo que demuestra la gran implicación en el proyecto por parte de la soprano, que, en esta fecha, 1914, ya era una gran figura de la ópera. Desde que debutara en 1898 en el Teatro de Novedades de Barcelona, Barrientos se convirtió en una de las figuras más aclamadas y con mayor prestigio de la ópera en el contexto internacional. A pesar de su retirada temporal de los escenarios entre 1907 y 1911, en el año 1914, fecha de la gira con el Orfeó, Barrientos ya se encontraba de nuevo inmersa en la actividad operística en los mejores teatros de todo el mundo.

Por otra parte, como antesala a esta colaboración con la agrupación musical catalana, cabe decir que María Barrientos, desde la temporada 1912-1913, mantuvo un vínculo especial con Cataluña. A este respecto, destaca la gira española que la

15. Orfeó Català (1914). Orfeó Català. Excursió artística a París i a Londres, Barcelona: Henrich y Comp, pp. 3-4. 
Barrientos comenzó en diciembre de 1912, siendo el teatro Principal de Barcelona el espacio elegido para el inicio de la misma. Asimismo, la cantante también participó en la programación de abono de los eventos de primavera del Teatro Liceo de Barcelona, interpretando los papeles protagonistas de La sonámbula, de Bellini, El barbero de Sevilla, de Rossini, y Sansón y Dalila, de Saint-Säens, los días 7 y 8 de enero de 1913.

Igualmente, María Barrientos gozó de una estrecha relación con Lluís Millet desde su juventud, un nexo profesional muy patente ya a comienzos de 1914 a través del Festival Haendel. El 19 de enero de 1914, el Palau de la Música Catalana acogió el Festival Haendel, una acción conjunta del Primer Premio Barrientos. La interpretación de la Oda Ceciliana de Haendel acaparó las dos primeras partes del evento, bajo con la dirección del propio Millet, la interpretación coral por parte del Orfeó y la interpretación solista a cargo de María Barrientos. En esta obra también participaron el propio Blai Net al piano, así como el tenor catalán Antoni Corte, el organista y compositor Vicenç Maria de Gibert y la Orquesta Sinfónica. La tercera parte del Festival Haendel estuvo formada por la interpretación de la «Obertura» de Coriolan, de Beethoven, las «Cancó de Maria» y «Cancó dels rossinyols», de Lamote de Grignon, la «Obertura» de Las bodas de Fígaro, de Mozart, y el aria «L'Aucellet» de la oda L'Allegro, il Penseroso ed il Moderato de Haendel. Este evento demuestra que, durante los meses previos a la gira, el vínculo de Barrientos con las instituciones catalanas y con el propio Lluís Millet era fuerte, de ahí que no sorprendiera la participación de la soprano en las actuaciones de Londres y París del Orfeó.

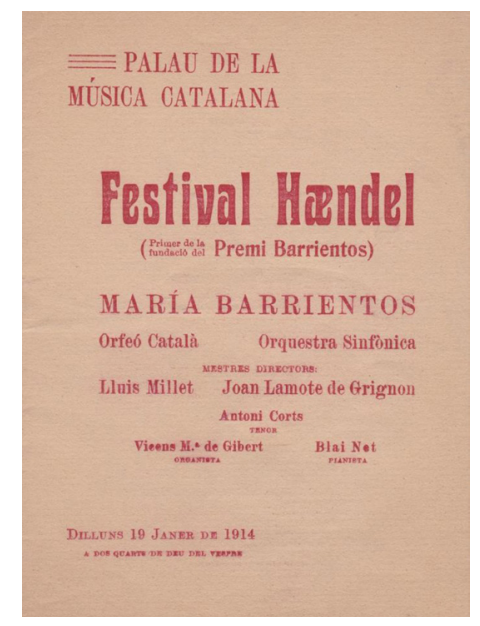

Figura 2. Programa del Festival Haendel. Fuente: Archivo Sánchez Rodríguez. 


\section{VIRGINIA SÁNCHEZ RODRÍGUEZ \\ EL ORFEÓ CATALÀ Y SUS CONCIERTOS PARISINOS DE 1914: DE LA ESTELA \\ DE UNA DIVA AL TRIUNFO DE LO POPULAR}

Por otra parte, continuando con la gira que nos concierte, cabe decir que, con la intención de mantener el orden en un grupo humano tan grande como el Orfeó Català, en el libro de viaje editado para distribuir entre sus miembros también se aprovechó para recordar algunas de las normas del reglamento. Al fin y al cabo, había que mantener el orden y la disciplina para el buen funcionamiento de la convivencia y la correcta celebración de los conciertos programados. En lo relativo a la normativa, además de los artículos relativos a la guarda de la compostura propios, especialmente se hace hincapié en el cuidado de la voz los días previos a las actuaciones. Véase al respecto el artículo 24:

Art. 24. Quan el cos choral surti de Ciutat haurà de seguir l'itinerari i fer el viatge en la forma disposada per la Junta Directiva. Durant el viatge els choristes no podrán cantar a chor, ni fer broma estrepitosament a l'objecte de conservar les facultats vocals i guardar la compostura precisa en tots els actes de l'Orfeó.

El viaje completo se extendió entre los días 11 y 26 de junio de 1914. En cuanto al transcurso del mismo, la primera parada tuvo lugar en la capital de Francia, que es el objeto de nuestro estudio. El Orfeó emprendió su marcha la mañana del 11 de junio de 1914 desde la Estación de Francia de Barcelona. Los miembros de la agrupación viajaron en segunda clase, para lo que habían reservado 2 vagones - uno para hombres y otro para mujeres -, y se había dispuesto otro vagón adicional en primera clase destinado a «aquets darrers, als Mestres, Junta Dirctiva, Metje, i demés persones que tinguin contrassenya-bitllet de primera clase (color rosa) $»^{16}$. La separación de espacios entre hombres y mujeres era una pauta social propia de la época; además, cabe señalar que las mujeres y los niños pudieron ir acompañados durante el viaje. La llegada a París estaba prevista para la tarde del 12 de junio, donde los miembros del Orfeó desembarcaron en la estación d'Orsay, donde fueron recibidos por los aplausos de otros compatriotas:

Ha llegado la célebre Sociedad coral Orfeó Català, compuesta de 250 individuos entre hombres, mujeres y niños, quienes fueron recibidos en la estación, en unión de los delegados del Ayuntamiento de Barcelona, por el presidente de la Cámara de Comercio española y por el presidente del Centro Catalán en París, señor Rigalt. Estos dos últimos dieron la bienvenida a los españoles, no solo en nombre de los respectivos centros, sino en el de cuantos españoles residentes en París se habían adherido a las fiestas en que la referida masa coral va a tomar parte.

En la estación había numerosos grupos de españoles, catalanes en su mayoría, y prorrumpieron en aplausos entusiastas ${ }^{17}$.

16. Orfeó Català. Orfeó Català. Excursió artística a París i a Londres..., Op. cit., p. 8.

17. $A B C, 14$ de junio de 1914, p. 15. 


\section{VIRGINIA SÁNCHEZ RODRÍGUEZ \\ EL ORFEÓ CATALÀ Y SUS CONCIERTOS PARISINOS DE 1914: DE LA ESTELA \\ DE UNA DIVA AL TRIUNFO DE LO POPULAR}

Una gran expectación rodeó el evento. Durante los días previos a las actuaciones, la prensa francesa ya se hizo eco de la llegada de la agrupación, acompañada por Barrientos, y de la programación de sus conciertos. Véase al respecto la noticia publicada en La Lanterne: journal politique quotidien, con fecha de 8 de junio de 1914:

L’Orfeó Català, la célèbre societé chorale mixte de Barcelone, composée de 250 exécutants (enfants, femmes et hommes), va donner à Paris deux grands concerts qui auront lieu en soirée le dimanche 14 juion, au théâtre des Champs-Elysées, et le mardi 16, au Trocadéro. Mme María Barrientos, la réputée cantatrice, et le ténor George Walter, prëtent leur concours à ces importantes manifestations dont les magnifiques programmes anoncent, notammente, la première audition à Paris du fameux Hymne pour seize voix à capella de Richard Strauss, presque inconnu à cause de sa difficulté d'exécution; de très intéressantes oeuvres espagnoles anciennes et modernes; de nombreuses chansons catalanes, merveilleuses de couleur et de caractère, etc. La location est ouverte au théâtre des Champs-Elysées, au Trocadéro et ches les éditeurs ${ }^{18}$.

Como se puede constatar, la expectación generada hacía hincapié en la gran fama de María Barrientos, del tenor George Walter y del propio Orfeó, así como en el interés del repertorio, que comprendía obras de concierto, pero también parte del imaginario popular en torno a la región de Cataluña, cuyas canciones catalanas son consideradas «maravillosas en color y carácter». Podría sorprender que la prensa destacara estas canciones catalanas, en lugar de ofrecer más detalle al repertorio propiamente culto; sin embargo, esta cuestión coincide con el exotismo en torno a la cultura hispana de comienzos del siglo XX en el extranjero.

Además de la prensa, las autoridades también se volcaron con los artistas españoles, que fueron recibidos incluso por el alcalde de París y acompañados por los mandatarios franceses a lo largo de un recorrido por la ciudad el día 13 de junio ${ }^{19}$, una recepción de la que también se hizo eco la prensa española ${ }^{20}$. Tal como se indica en el Bulletin Municipal Officiel de la Ville de Paris, además de Millet y los artistas españoles implicados en la gira, junto a los orfeonistas también viajaron grandes autoridades, desde miembros del Ayuntamiento de Barcelona hasta diputados como Cambó o el presidente fundador del Centre Català de París:

Le samedi 13 juin, à trois heures de l'après-midi, la Municipalité de Paris a reçu, dans les salons de l'Hôtel de Ville, les membres de la Societé chorale l'Orfeó Català de

18. La Lanterne: journal politique quotidien, 8 de junio de 1914, p. 3.

19. Bulletin Municipal Officiel de la Ville de Paris, año XXXIII, no 170, pp. 2515-2518.

20. «En el Ayuntamiento se ha celebrado una recepción en honor del Orfeó Català, ejecutando éste varias composiciones (...)». La época, 15 de junio de 1914, p. 1. 
VIRGINIA SÁNCHEZ RODRÍGUEZ

EL ORFEÓ CATALÀ Y SUS CONCIERTOS PARISINOS DE 1914: DE LA ESTELA

DE UNA DIVA AL TRIUNFO DE LO POPULAR

Barcelone, qui étaient accompagnés de MM. Pedro Muntanola et Martin Martons, adjoints à l'Alcade de Barcelone; José de Lasarte, conseiller municipal; Cambo et E. Bertrand, députés; E. Calvet, sénateur; Cabot, membre de la Députation provinciale; Millet, directeur fondateus et François Matheu, président de l'Orfeó Català; Pierre Balmana, président fondateur du Centre Català de Paris; Escalas, délégué de la Chambre de Commerce de Barcelone; Escofet, Bertran et Morato, représentants de la Presse de Barcelone ${ }^{21}$.

El despliegue de una comitiva de tal magnitud demuestra que el viaje no era una simple excursión artística, sino un proyecto cultural destinado a mostrar a Europa el talento musical de los componentes de la institución catalana y el buen hacer de los máximos responsables de la misma. Por otra parte, durante la estancia en la ciudad, los componentes, además de cantar, realizaron visitas culturales a algunos de los monumentos más emblemáticos e incluso a industrias hispanas asentadas en las inmediaciones de la capital de Francia ${ }^{22}$.

En lo que respecta a las actuaciones en sí, en París se ofrecieron dos conciertos. El primero de ellos tuvo lugar el 14 de junio en el teatro de los Campos Elíseos. En cuanto al repertorio ${ }^{23}$, además de la interpretación de canciones de Clavé, Pedrell, Granados y Nicolau, del Ave verum de Saint-Saens, de composiciones de Brudieu, Jannequin, Josquin y Victoria y del «Credo» de la Misa del Papa Marcelo de Palestrina, el tono más folklórico del primer concierto parisino lo comprendía el «Cant de la Senyera» de Millet, a seis voces, compuesto por el director de la agrupación como himno del propio Orfeó, y siete canciones populares catalanas de Moreira, Romeu, Mas Serracant, Lambert, Millet, Noguera y Cumellas Ribo.

María Barrientos, que aparece anunciada con letras de mayor tamaño en el cartel del evento, finalmente no pudo participar en este programa, eminentemente coral y con evidentes tintes populares, debido a un accidente. Asimismo, la soprano tampoco pudo actuar en el segundo evento programado en suelo francés junto a la institución catalana debido al reposo recomendado, tal como lo recoge la prensa de la época un par de días previos al debut del Orfeó:

Un regrettable accident mettant Mme Barrientos dans l'impossibilité de chanter avant une semaine et privant l'Orfeó Català de son concours. L’Ode à Sainte Cécile qui devait être donnée mardi au Trocadéro sera suprimée.

21. Bulletin Municipal Officiel de la Ville de Paris, año XXXIII, n 170, pp. 2515-2516.

22. «Una brillante y nutrida representación del Orfeó Català ha visitado la nueva fábrica construida en Bois Colombes por la Sociedad Española de Automóviles La Hispano-Suiza, admirando los vastos terrenos adquiridos, los magníficos talleres edificados y la soberbia instalación de maquinaria, donde pueden verse todos los adelantos modernos». $A B C, 18$ de junio de 1914, p. 21.

23. Vid. el cartel del evento. Disponible en: http://mdc.csuc.cat/cdm/landingpage/collection/CartCEDOC [Última consulta: 21 de junio de 2018]. 


\section{VIRGINIA SÁNCHEZ RODRÍGUEZ \\ EL ORFEÓ CATALÀ Y SUS CONCIERTOS PARISINOS DE 1914: DE LA ESTELA \\ DE UNA DIVA AL TRIUNFO DE LO POPULAR}

Tout un numéro de musique de danses populaires sera ajouté, exécuté sur les instruments caracteristiques locaux.

Quant au programme d'après-demain dimanche au théâtre des Champs-Elysées, sauf un morceau que devait chanter Mme Barrientos, il demeure inégralemente maintenu ${ }^{24}$.

En todo caso, y a pesar de esta ausencia, el primer concierto fue todo un éxito, como demuestran las excelentes críticas en los medios franceses. Véase al respecto la reseña publicada por el crítico y musicólogo Henri Quittard (1864-1919) para Le Figaro, uno de los periódicos más prestigiosos del país, tras la primera actuación del Orfeó en suelo francés. Como se puede comprobar, el Orfeó Català es destacado por encima de otras agrupaciones corales internacionales. Además, junto con la excelente técnica interpretativa, Quittard también señala la delicia de las obras del programa de perfil popular:

Maintes fois nous avions déjà eu, à Paris, l'occasion d'entendre d'illustres compagnies chorales. Choeurs anglais, hollandais, allemands ou russes, choeurs de théâtre ou de concert nous avaient charmés par une supériorité d'exécution de quoi jusqu'ici il n'a été donné aux ensembles français les plur réputés de n’approcher que de très loin. Mais ces auditions diverses ne nous enlevaient pas l'espoir d'arriver quelque jour à égaler - ou presque - tel de ces groupes d'artistes qu'il nous était donnée d'entendre. Aussi bien n'en était-il aucun qui réunit en soi tous les mérites. Tel se distinguait par la qualité des voix. Tel autre par la verve et la précision de l'ensemble. Tel autre encore par le nombre imposant de chanteurs exercés, réunis sous la direction du chef.

C'en était bien assez d'ailleurs pour imoser, bon gré malgré, une comparaison un peu humiliante pour l'amour-propre national. Mais avant-hier, voici que l'Orfeó Català est venu donner son premier concert. Il faut bien confesser que jamais nous n'avions rien entendu qui approchât de cet extraordinaire ensemble. Les deux cent soixante choristes de Barcelone laissent bien loin derrière eux les sociétés les plur réputées de ces paus du Nord où l'art choral est particulièrement en honneur. Et pour ce qui regarde la France, qui pourrait seulemenet concevoir la pensée que l'organisation d'un tel choeur soit jamais chez nous possible?

Trop de choses, en vérité, nous l'interdisent. L'Orfeó Català, ainsi que toutes les grandes sociétés chorales de l'étranger, n'est pas un ensemble de professionnels. Pour amener de simples amateurs, choisis avec discernement, à un tel degré d'habileté et de talent, un long effort, prolongé pendant des années, est indispensable. Et chez nous, trop de causes de division, politiques ou autres, ne permettent nulle part un effort, volontaire en commun, de quelque durée. Voici vingt-trois ans que M. Lluís Millet fondait à Barcelone l'Orfeó Català. Il ne réunissait alons que vingt-huit

24. L'Aurore: littéraire, artistique, sociale, no 6035, 12 de junio de 1914, p. 3. 
VIRGINIA SÁNCHEZ RODRÍGUEZ

EL ORFEÓ CATALÀ Y SUS CONCIERTOS PARISINOS DE 1914: DE LA ESTELA

DE UNA DIVA AL TRIUNFO DE LO POPULAR

exécutants. Ce modeste ensemble est aujourd'hui décuplé et les ambitions de la Société comme ses possibilités artistiques se sont singulièrement accrues. Cependant le même chef préside à ses destins. Depuis vingt-trois ans, un même esprit l'anime, une même doctrine préside à l'éducation et à la culture musicale de ses membres. Sans une tradition aussi rigoureusement suivie, sans une unité d'inspiration aussi parfaite, un résultat pareil ne saurait être atteint.

Ce résultat est simplement admirable. Autant qu'on en puisse juger pour un si considérable groupement, la qualité des voix - pour les hommes - ne semble pas extraordinaire, cependant. Mais quelle fraîcheur de timbre, quelles pureté, quelles justesse! Il faut à ces chanteurs une technique surprenante pour réaliser avec une perfection aussi absolue les effets de douceur incomparable où ils excelllent. Et il n'est pas moins merveilleux d'entendre l'harmonieuse fusion de tant de voix, l'équilibre surprenant des sonorités, l'égalité parfaite de tous les registres de ce vaste clavier, docile à l'impulsion du chef comme le serait celui d'un orgue sous les doigts d'un virtuose habile.

Il est naturel qu'un ensemble aussi produgieux ait encouragé d'excellents compositeurs à écrire pour lui de grandes oeuvres. Le programme comprenait trois de ces compositions qui n'ont, comme on le pense bien, qu'un très lointain rapport avec les choeurs destinés, chez nous, aux orphéons.

La légende de Pedrell, «Don Joan i don Ramon», et la «Mort de l'enfant de choeur», d'un musicien catalan moderne, Nicolaù, ont paru d'un très beau sentiment expressif et d'une facture aussi ingénieuse et aussi variée que peut le comporter un genre forcément borné en ses effets.

De délicieuses chansons populaires catalanes formaient la première partie $d u$ programme. Très variées, très originales, ces petites pièces, harmonisées avec une fantaisie charmante, ont obtenu le succès le plu vif. Et après un Ave Verum de Saint-Saëns, d'une ligne mélodique, soulple el fluide, et d'une admirable pureté d'écriture, la soirée s'est achevée triomphante pas l'exécution de quelques oeuvres, religieuses ou profanes du seizième siècle.

Le «Credo» de la Messe du pape Marcel de Palestrina terminait cette série de belles oeubres. J'aime mieux dire tout de suite, puisque l'occasion m'en est donnée, que je n'ai pas pour Palestrina autant d'admiration - ni si exclusive - qu'on a accoutumé de lui témoigner. C'est un gran maître, assurément, mais d'un académisme un peu froid. Dans l'admirable pléiade des maîtres de son temps, plusieurs autres ont mes préférences. Mais il n’importe. M. Lluís Millet donna de ce morceau un interprétation si belle, si grande, si magnifiquement ordonnée, qu'il ne semblait pas qu'on l'eût, jusqu'ici, véritablement entendu. Une pareille réalisation est, en vérité, d'un très grand artiste ${ }^{25}$.

Además de ensalzar la calidad de la interpretación del repertorio culto, en la crítica se destacan las canciones corales populares, «armonizadas con una fantasía

25. Le Figaro, 16 de junio de 1914, p. 5. 
VIRGINIA SÁNCHEZ RODRÍGUEZ

EL ORFEÓ CATALÀ Y SUS CONCIERTOS PARISINOS DE 1914: DE LA ESTELA

DE UNA DIVA AL TRIUNFO DE LO POPULAR

encantadora, que han obtenido el éxito más vivo». La calurosa acogida del Orfeó Català en su primera actuación en París también fue recogida por los medios españoles ${ }^{26}$. Entre otros, véase al respecto la portada de El Correo Español del día 15 de junio de 1914, donde se señala, con detalle y orgullo, la presencia de autoridades entre el público, la entrega de un galardón a Lluís Millet y los resonantes vítores a los miembros del Orfeó:

\section{El primer concierto ha sido un triunfo brillantísimo.}

PARÍS 14. Esta noche se ha celebrado el primer concierto, dado por el Orfeó Català, verificándose el acto en el teatro de los Campos Elíseos a beneficio de obras de beneficencia de Barcelona.

El coliseo estaba atestado de distinguidísima concurrencia, asistiendo al mismo el embajador de España y la Marquesa de Villaurrutia, y lo más elegante de la sociedad parisina.

Con el embajador ocupaban la presidencia de honor el presidente del Centro Català y otras distinguidas y caracterizadas personalidades españolas.

En la primera parte del programa, formada por canciones populares, originales de autores españoles, cuya ejecución ha sido objeto de prolongados aplausos, y en medio de una ovación atronadora y de vivas a España y a Cataluña, el director recibió una palma de laurel, atada con cintas de colores nacionales.

La segunda parte del programa fue ejecutada con la misma maestría, y en un entreacto, el presidente del Centre Català, entregó al director del Orfeó Català un grupo en bronce, representando la música, y la señora de Pedregal una magnífica palma.

Los orfeonistas terminaron en medio de atronadores aplausos, produciendo la ejecución del programa la admiración de los concurrentes, que se retiraron satisfechísimo de la velada ${ }^{27}$.

El diario $A B C$ también se hizo eco del éxito, aunque, más que aspectos musicales, se ofrecen referencias a aspectos sociales. En concreto, como se observa en la escueta y superficial reseña publicada el 15 de junio de 1914, se reiteran las citas a las autoridades españolas presentes, las ovaciones a los orfeonistas y las alabanzas «a España y a Cataluña»:

París 15, 1 madrugada. En el teatro de los Campos Elíseos se ha celebrado esta noche el primer concierto dado por el Orfeó Català.

La función, que ha sido a favor de las obras de beneficencia de Barcelona, ha resultado brillantísima.

26. El Globo, 15 de junio de 1914, p. 2; El imparcial, 15 de junio de 1914, p. 1; El Correo Español, 17 de junio de 1914, p. 1; La Correspondencia, 15 de junio de 1914, p. 2.

27. El Correo Español, 15 de junio de 1914, p. 1. 
VIRGINIA SÁNCHEZ RODRÍGUEZ

EL ORFEÓ CATALÀ Y SUS CONCIERTOS PARISINOS DE 1914: DE LA ESTELA

DE UNA DIVA AL TRIUNFO DE LO POPULAR

Ocupaba la presidencia de honor el embajador de España con el presidente del Centro Catalán, y asistieron la marquesa de Villa Urrutia y lo más elegante de la sociedad parisiense.

En la primera parte del programa se interpretaron canciones populares originales de autores españoles. Fueron muy aplaudidas, y se dieron vivas a España y a Cataluña. Al final del concierto se repitieron las ovaciones ${ }^{28}$.

Por su parte, el diario La Vanguardia llevó a cabo un seguimiento pormenorizado de todo el viaje de la célebre agrupación barcelonesa. El periodista José Escofet (1884-1939) fue el encargado de acompañar al Orfeó y de trasladar, a través del citado periódico, las vivencias de los componentes y la incidencia del orfeón en suelo francés. Además de hacerse eco de las visitas culturales llevadas a cabo por los orfeonistas, en su crónica publicada el 15 de junio de 1914 también se hizo eco del éxito grandioso de la sociedad coral, con el detalle también de cuestiones puramente musicales:

Esta noche se ha celebrado en el teatro de los Campos Elíseos el primer concierto que da en París el Orfeó Cátala, acontecimiento artístico que era esperado con gran interés por los inteligentes. Este primer concierto, que era a beneficio de las entidades benéficas de Barcelona, ha atraído una numerosa y elegante multitud al coquetón teatro de los Campos Elíseos. Ocuparon los palcos el embajador de España, señor marqués de Villaurrutia y su señora; los señores Rigalt y Botella, presidente y vicepresidente de la Cámara de Comercio española; Bosch, presidente honorario y Balmañá, presidente efectivo del Centre Catalán de París; el doctor Cabos, presidente del Círculo HispanoAmericano; el secretario de la Cámara de Comercio española, señor Viñas Roca y su señora, y numerosas familias de la colonia catalana. Entre las personalidades francesas que han asistido a la fiesta, figuraban: MM. Gabriel Fauré, Eugenio Gigoux, Claudio Debussy, Mauricio Ravel, Pablo Ducas, Jaime Rouche, Alfredo Bruneau, Pedro Lalo, Ebrart y Hahn; las señoras de André, Escoffier, Rejane y Chantevoine; el señor y la señora Fuchs y otros muchos. El teatro estaba lleno.

Al aparecer en el escenario los ejecutantes en número de doscientos cincuenta, formando un coro mixto, han sido saludados con una nutrida salva de aplausos. Seguidamente el maestro Millet ha ocupado su puesto, empezando el concierto, que ha sido escuchado con profunda atención.

Componían el programa un ciclo de cantos populares, algunas obras de autores españoles, después un coro de Jannequin y el Ave verum de Saint Saens, y por último algunos fragmentos de la Misa del Papa. Marcelo, de Palestrina.

Los cantos populares catalanes han obtenido grandioso éxito. El público, que ha aclamado calurosamente al Orfeó, ha pedido con insistencia oír otra vez algunas de

28. $A B C, 15$ de junio de 1914 , p. 19. 
VIRGINIA SÁNCHEZ RODRÍGUEZ

EL ORFEÓ CATALÀ Y SUS CONCIERTOS PARISINOS DE 1914: DE LA ESTELA

DE UNA DIVA AL TRIUNFO DE LO POPULAR

las piezas, teniendo que repetirse «Els tres tambors» $\mathrm{y}$ «El cants dels aucells». De las composiciones originales, «La mort del escolà», del maestro Nicolau, ha sido acogida por el público con largos y calurosos anplausos, ovacionando al director, señor Millet.

Éste, en medio de los aplausos y los vivas del público, fue obsequiado con una magnífica palma de laurel, adornada con lazos de los colores franco-españoles.

Durante el entreacto los asistentes han hecho un caluroso elogio de la irreprochable ejecución de los artistas catalanes.

\section{Más del concierto-Ovación delirante.}

En la segunda parte del concierto obtuvo igualmente el Orfeó un gran éxito.

Esta parte se componía de obras maestras del siglo XVI, que fueron saboreadas con agrado por la concurrencia, la que aplaudió frenéticamente repetidas veces. Después de la ejecución del O Magnum Misterium, de Victoria, don Pedro Balmaña, presidente del Centre Cátala, subió al escenario, entregando al director del Orfeó un bronce representando la Música.

El concierto terminó con el «Credo» de la Misa del Papa Marcelo, de Palestrina. El auditorio, emocionado ante esta joya del arte musical, manifestó su entusiasmo aclamando durante cerca de un cuarto de hora al Orfeó Cátala. La señora Mercedes Regalt obsequió a las señoritas orfeonistas con magníficos ramos de flores. El maestro Millet y los orfeonistas se muestran muy satisfechos del éxito obtenido ante el público parisién ${ }^{29}$.

En relación con el resto de críticas sobre esta primera actuación, cabe señalar que Escofet suscribe el éxito que también se evidencia en el resto de medios franceses y españoles, pero también menciona las personalidades que asistieron a esta primera gran actuación del Orfeó. A modo de argumento de autoridad, Escofet menciona la presencia de algunos de los grandes compositores franceses del momento, como Fauré, Dukas, Debussy o Ravel. La referencia a estas personalidades en la crónica ofrece aún mayor boato a una actuación memorable.

Un día después, el día 16 de junio, Escofet escribió una nueva reseña en la que, tras la detallada crítica del evento publicada el día anterior, señaló la presencia social de la cultura popular en suelo francés a través de la vestimenta de algunas orfeonistas y de otras españolas que se pasearon con mantilla blanca en las calles de París. Aunque se aprecia una voluntad de integración en la idea global de España, Escofet también señala el interés de los catalanes de diferenciarse del resto de la Península Ibérica, lo que, según el crítico, queda patente especialmente a través del programa musical de los conciertos:

Media hora después de haber hecho el señor Muntañola una vibrante demostración de catalanidad en el Hotel de Ville, pronunciando ante el alcalde de París un breve

29. La Vanguardia, 15 de junio de 1914, p. 10. 
VIRGINIA SÁNCHEZ RODRÍGUEZ

EL ORFEÓ CATALÀ Y SUS CONCIERTOS PARISINOS DE 1914: DE LA ESTELA

DE UNA DIVA AL TRIUNFO DE LO POPULAR

discurso para que destacara Barcelona del resto de España-para que destacara hemos dicho, no para separarla de su fondo de vida española; - media hora después de haberse oído el «Cant á la senyera» en aquellos salones suntuosos del palacio del Ayuntamiento -, algunas coristas daban una nota de españolismo en la calle de Rivoli con sus mantillas blancas. A un español residente en París que no supiera la llegada del Orfeó, aquellas mujeres que paseaban por la calle de Rivoli en coche y con mantilla blanca le habrían producido una emoción profunda: Figuraos una gran avenida parisiense por la que van y vienen constantemente coches de alquiler, autos; ómnibus, tranvías; un movimiento rodado alegre - el movimiento de París es siempre alegre - y mujeres tocadas con la clásica mantilla. El español cree que está soñando. ¿Qué ocurre en París? ¿Hay toros en París? ¿Está en la rue de Rivoli o en la calle de Alcalá en día de corrida? Se pasa la mano por los ojos y mira al cielo. El cielo es gris; cae una lluvia pulverizada y lenta. Observa los carruajes, los balcones, los establecimientos, y todo le habla en francés. Sin duda está en París; pero: aquellas mujeres... Y la evocación es inevitable: el español se acuerda de la calle de Alcalá, si es de Madrid, o de la de Pelayo, si es dé Barcelona. Y acaso no le gusten los toros; pero aquellas mantillas asociadas al movimiento de la calle y a la nostalgia de la patria, cuya alegría ha de parecer siempre torera al desterrado, le conmueven, le emocionan. El amor prescinde frecuentemente de las ideas, y el patriotismo es amor. El público francés quizás no se dio cuenta de las mantillas. En París nada de lo que se exhibe en la calle produce sorpresa. En las calles de aquí se exhibe todo lo feo, y todo lo bonito y todo lo pintoresco del mundo. El mundo envía muestras de su producción a París, y París es un muestrario formidable, encantador y revuelto. Este París que ve reyes, príncipes, bohemios, hombres de todos los países vistiendo sus trajes populares, mujeres muy bien vestidas y otras muy bien desnudas, moros, chinos, todo lo raro, en fin, ¿ de qué puede asombrarse? Vio pasar unas cuántas mujeres con mantilla blanca y pensó, probablemente, que eran señoras de la aristocracia española que le visitaban. Visten un poco mal estas señoras, se dirían las elegantes, al fijarse en los trajes modestos de nuestras orfeonistas. Y nada más.

En la calle todos los catalanes somos españoles, solo españoles; fue en Hôtel de Ville donde, además, fuimos catalanes. De Cataluña hablaron elocuentemente los señores Cabot y Muntañola al alcalde, al prefecto del Sena y al de Policía. Sin embargo, estos señores no debieron entender muy bien, a pesar del francés correctísimo de Cabot y Múntañola, y al contestar se refirieron a España, a toda España. Entonces tuvo que habar Villaurrutia, naturalmente. Pero yo estoy en que quien habló más fue el Orfeó. Por lo menos, al estallar entusiasta el aplauso, después de sus canciones populares, se demostró que le habían entendido. No obstante cantar en catalán, lo que tiene más significación y trascendencia. Pero el Orfeó Cátala se hará entender en París y en Londres y en todas partes donde se ame la música. Y lo malo, o lo bueno (ya lo discutiréis vosotros ahí, paisanos míos), es que en todas partes va a parecer simplemente español. Fuera de España, en Europa nadie entiende el español. Esto, que le asombraba y le indignaba, a la vez, a la mamá de 
VIRGINIA SÁNCHEZ RODRÍGUEZ

EL ORFEÓ CATALÀ Y SUS CONCIERTOS PARISINOS DE 1914: DE LA ESTELA

DE UNA DIVA AL TRIUNFO DE LO POPULAR

una orfeonista, empeñada en hablar en castellano a un camarero, y empeñado el camarero en tomarla por rusa, es rigurosamente exacto. Los europeos de categoría, como estos de París y los que conoceremos en Londres, no entienden el idioma de Cervantes, y da lo mismo hablarles el de Verdaguer. Para ellos tan español es el uno como el otro, y mucho me temo que el francés o el inglés que oigan ahora el Orfeó y vayan después a Madrid, van a preguntarles a los madrileños por la Mare de Deu de la Paloma. Mare de Deu no será, para esta gente, ni más ni menos que la Vierge o the Virgin en español.

Todo esto se me ocurría viendo pasar por la calle de Rivoli mujeres tocadas con mantilla blanca. Si hubieran llevado también flores y hubiese brillado un poco el sol en el cielo parisiense, la ilusión habría sido perfecta. Una tarde de España y de domingo metida en el cerebro de Europa. Muy bonito. Cosas peores se le meten a Europa en el cerebro.

A mí-lo diré francamente-este inevitable carácter español que acompaña al Orfeó Cátala no me desagrada. Para los franceses y para los ingleses todos los hijos de España somos españoles; pero entre los españoles nos distinguimos especialmente los catalanes. Si el Orfeó nos ayuda a ser españoles distinguidos, miel sobre hojuelas. Sería una distinción de cultura artística que nos tendría en cuenta España, como nos tiene en cuenta ya otras distinciones. Aquí triunfaría España con el Orfeó, lo que no está mal; pero mientras tanto en España triunfará Cataluña, que todavía es mejor. Y esto vamos ganando los catalanes.

De suerte que, si ahora les decía el señor Muntañola, acaso sin eficacia, a las autoridades de París, que se fijaran bien en que el Orfeó era catalán, en España no hará falta semejante advertencia: ya lo saben todos los españoles. De lo cual nos alegramos mucho ${ }^{30}$.

Más allá de estas reflexiones de carácter político más que artístico publicadas en La Vanguardia, lo cierto es que el resto de medios, peninsulares y franceses, coinciden en el valor musical del Orfeó y de sus interpretaciones en el primer evento ofrecido en la capital francesa. No obstante, como corresponsal de un medio catalán a una gira que pretende ponderar la cultura popular de la región, consideramos comprensible el parecer de Escofet.

El segundo concierto, ofrecido en el Teatro del Trocadero, se celebró el 16 de junio y fue igualmente aclamado. El periódico Le XIXe siècle: journal quotidien politique et littéraire no solo reiteró el impedimento de Barrientos también en este evento, sino que, además, ofreció numerosos detalles sobre la modificación del programa en favor de un repertorio con tintes más regionalistas. Inicialmente, en el programa se destacaban, por encima de la agrupación, las figuras de María Barrientos y el tenor americano George A. Walter (1875-1952), especialmente laureado por sus interpretaciones del repertorio bachiano y haendeliano, para la

30. La Vanguardia, 16 de junio de 1914, p. 8. 
VIRGINIA SÁNCHEZ RODRÍGUEZ

EL ORFEÓ CATALÀ Y SUS CONCIERTOS PARISINOS DE 1914: DE LA ESTELA

DE UNA DIVA AL TRIUNFO DE LO POPULAR

interpretación de la Oda Ceciliana de Haendel. Sin embargo, en lugar de la obra barroca programada, como solución, se optó por la inserción de danzas populares interpretadas por la Cobla La Principal de Peralada bajo la batuta de su director Josep Serra (1874-1939), que acudió a París expresamente para suplir la ausencia de la soprano catalana. La Cobla de Peralada, fundada en 1890, se caracterizaba por su prestigio y su dominio del repertorio instrumental popular. La sustitución de la obra de Haendel por un conjunto de danzas instrumentales de Cataluña otorgó aún más tintes populares al evento, lo que supuso la extrapolación de una pequeña parte del folklore catalán en suelo parisino.

Un regrettable accidente, mettant Mme Barrientos dans l'impossibilité de chanter avant une semaine et privant l'Orfeó Català de son concours, l'Ode à Sainte-Cécile, qui devait être donnée mardi, au Trocadéro, sera supprimée. Et une modification qui réjoura les nombreux amateus de couleur locale et de l'art espagnol sera apportée à ce programme: tout un numéro de musique de danses populaires y sera ajouté, exécuté sur les instruments caractéristiques locaux par la fameuse Cobla Peralada, qui viendra spécialmente à Paris dans ce but ${ }^{31}$.

El resto del programa vocal previsto se mantuvo en este segundo concierto de París. Así, y tras la interpretación del «Cant de la senyera» de Millet, que se convirtió en la pieza de obertura de todos los conciertos de la gira - también en Londres-, se escucharon cinco canciones populares catalanas de Perez, Pujol, Manen, Sancho Maracco y Nicolau, el motete BWV 225 «Singet dem Herrn ein neues» de Bach y el Hymne a 16 voces de Richard Strauss, todo ello seguido de las danzas populares catalanas interpretadas por la citada cobla.

La actuación fue todo un éxito. A pesar de que María Barrientos era un gran reclamo en la gira internacional del Orfeó, tal como indicaban las primeras notas de prensa y como corroboraba el tamaño de su nombre en los programas de ambos conciertos, finalmente la sociedad coral recibió el reconocimiento merecido gracias a su calidad musical y al colorido del repertorio popular entonado. Véase como ejemplo significativo un extracto de la crítica contenida en el periódico francés Gil Blas, el medio creado por Auguste Dumont (1816-1885), con fecha de 17 de junio de 1914:

L'Orfeó Català et son exemple

L'Orfeó Català nous a donné, hier soir, au Trocadéro, un deuxième et dernier concert. Des chansons et des danses catalanes composaient tout naturellement, le pittoresque de cette harmonieuse solennité. On les louera judicieusement, je crois, en disant qu'elles sonnet clair et beau l'amour. Une volupté tour à tour tangoureuse

31. Le XIXe siècle: journal quotidien politique et littéraire, $\mathrm{n}^{\circ} 16193,15$ de junio de 1914, p. 4. 
VIRGINIA SÁNCHEZ RODRÍGUEZ

EL ORFEÓ CATALÀ Y SUS CONCIERTOS PARISINOS DE 1914: DE LA ESTELA

DE UNA DIVA AL TRIUNFO DE LO POPULAR

ou frénétique s'y confié, s’y émeut, s'y ingénie avec une étonnante loyauté ; cette musique-là se ressent profondément de la gloire incomparable du soleil.

M. Lluis Miliet et les anonymes et étonnants artistes de l'Orfeó Català l'ont interpreté avec un enthousiasme, avec une foi, qui ajoutait à la perfection de l'art de la chaleur même de la vie.

Ils ne furent pas moins ardents ni moins impeccables dans l'interprétation d'autres oeuvres, où la Catalogne n'était plus présente. L'exécution d'un Hymne à seize voix, de M. Richard Strauss, peut être donné en exemple à tous les choristes de l'univers et d'abord aux choristes français.

Nous n'oublierons point la visite que nous a faite l'Orfeó Català. Il serait bien que le souvenir que nous en garderon se résolût en une leçon pour ceux qui, en France, ont quelque souci de l'art choral ${ }^{32}$.

El enaltecimiento de la calidad musical de la agrupación es la tónica dominante de todas las críticas. Henri Quittard, para Le Figaro, coincide también en las alabanzas hacia la institución catalana tras su segundo concierto en París. En su crítica destaca el encanto del repertorio tradicional, especialmente a través de la labor de la Cobla de Peraleda, y también señala, como realizó en la crítica del primer concierto, la gran técnica vocal del Orfeó en la interpretación de obras de gran complejidad, incluso en el Hymno a 16 voces de Strauss, que considera un tanto mediocre, a pesar de la maestría de Strauss en otras obras.

Le succès du deuxième et dernier concert de l'Orfeó Català, donné avant-hier au Trocadéro, ne fut pas moins triomphal que celui qui avait accueilli la première audition de cette admirable compagnie d'artistes. Il suffirait donc de répéter, en l'honneur de M. Lluís Millet et des chanteurs qu'il dirige avec une foi artistique si ardente, les éloges qui demeurent bien en deçà de leur médite. Cependant, la composition du programme de ce second concert, du moins, peut justifier quelques remarques. L'art catalan, en ce qu'il a de plus original, y était représenté pas un choix de nouvelles channsons populaires dont la verve ingénieuse, la grâce et le sentiment plaisant ou tendre ne le cèdent en rien à celles qui furent applaudies l'autre jour. Un delicieux intermède instrumental faisait suite à cette première partie. Car un orchestre populaire, la Cobla Peralada, nous fit entendre quelques airs de danse d'une saveur singulièrement caractéristique.

Par la sonorité tout d'abord. Le timbre agreste et nasillard des petits et grand hautbouis, chargés de sonner le thème des chansons, s'y marie de façon bien divertissante aux agiles fioritures de la petite flûte comme au bourdonnement d'un tambourin obstiné. Mais plur caractéristique encore semblent les thèmes que colore cette instrumentation pittoresque et rustique. L'originalité et la vigueur du rythme, la

32. Gil Blas, 17 de junio de 1914, p. 4.

Ediciones Universidad de Salamanca / 
VIRGINIA SÁNCHEZ RODRÍGUEZ

EL ORFEÓ CATALÀ Y SUS CONCIERTOS PARISINOS DE 1914: DE LA ESTELA

DE UNA DIVA AL TRIUNFO DE LO POPULAR

souplesse onduleuse de la ligne mélodique, l'intensité du sentiment expressif, la musicalité pour tout dire, y sont tout à fait remarquables.

Deux grandes oeuvres chorales, entièrement étrangères à la Catalogne, terminaient le concert, et la première, de composition, je crois, assez récente, avait ici le mérite de la nouveauté. C'était un gran Hymne de Richard Strauss, écrit pour seize voix en deux choeurs. Il faut bien dire que l'audition de cet ouvrage cause une déception presque générale. L'inspiration en est tout à fait ordinaire et l'écriture chorale, compliquée à l'excès, manque des qualités les plur essentielles à ce genre. Si travaillée qu'elle soit, si ingénieuse qu'assurément elle doive se révéler à la lecture, cette composition parait, à l'audition, d'effet médiocre. Q'un maître de la valeur de R. Strauss et si merveilleusement expert aux combinaisons de l'orchestre n'ait su que si mal tirer parti des voix, c'est chose assez étrange. Il serait bien curieux, si l'on était de loisir, d'en déduire les raisons par le détail.

Mais l'exécution de cet ouvrage, franchement manqué mais de difficulté singulièrement ardue, ne fait pas à l'Orfeó Català, un médiocre honneur. Celle du motet de Bach, «Chantez au Seigneur un cantique nouveau », qui suivait immédiatement, ne fut pas moins parfaite. Et là, du moins, la solide beauté de la musique répondait au talent des exécutant et legitimait leur noble effort ${ }^{33}$.

Por su parte, Le Temps, uno de los periódicos franceses más importantes de su época, también destinó espacio para hacer una crónica positiva, de forma conjunta a los dos conciertos ofrecidos por la agrupación española. En ella, el crítico Pierre Lalo (1886-1943), hijo del compositor Édouard Lalo (1823-1892), comienza evocando un recuerdo personal sobre los impactantes sonidos de un viaje a Cataluña que rememoró con motivo de la interpretación del Orfeó Català en sus dos conciertos parisinos. Lalo se deshacerse en halagos sobre la superioridad de esta institución y el buen hacer de sus componentes, coincidiendo con las críticas anteriormente referenciadas, y no duda en señalar que «sin duda, se trata de una de las mejores asociaciones corales que haya en el mundo»:

Il y a quelques années, le hasard d'un voyage m'avait conduit dans une petite ville de Catalogne. C'était Gérone, antique cité, dont les remparts dorés par les siècles et par le soleil ont soutenu l'assaut des chevaliers de Philippe le Hardi et des soldats de Napoléon. J'avais passé le jour à parcourir les sombres ruelles de la citadelle seigneuriale, à explorer l'ombre austère des cloîtres et les ténèbres tragiquement espagnoles des églises. Le soir, dans la pittoresque fonda où j'étais hébergé, vieille demeure aux balcons de pierre ciselée, aux murs ornés d'écussons poudreux, un bruit de pas et de voix attira soudainement aux fenêtres tous les gens de l'hôtellerie, étrangers, maîtres et serviteurs : parmi les hôtes de l'auberge, se trouvaient à ce moment deux membres des Cortès, à qui leurs électeurs venaient donnes une sérénade. Ce fut un

33. Le Figaro, 18 de junio de 1914, p. 5. 
VIRGINIA SÁNCHEZ RODRÍGUEZ

EL ORFEÓ CATALÀ Y SUS CONCIERTOS PARISINOS DE 1914: DE LA ESTELA DE UNA DIVA AL TRIUNFO DE LO POPULAR

divertissement merveilleux. Au fond de la rue étroite, devant la porte de la fonda, une cinquantaine d'hommes étaient groupés, portant le bonnet rouge qui est la coiffure du peuple catalan. Ils étaient éclairés par des torches, dont les flammes jetaient de grandes lueurs mouvantes dans les ténèbres de la rue, sur les visages de la foule et sur les murs des maisons. Ils commencèrent à chanter; je ne pene pas avoir jamais entendu un choeur plus admirable: même chez les Norvégiens ou chez les Russes, je n'ai jamais rencontré plus de justesse et plus de précision, plus de saveur et plus de couleur populaires, ni sustout un sens du rythme plus spontané, plus fort et plus saisissant. Ils chantèrent d'abord la Marseillaise, qui est en Catalogne le symbole des libertés provinciales, une Marseillaise étrangement transformée, à laquelle des entrées successives des voix donnaient un curieux caractère d'archaïsme, puis ils exécutèrent diverses chansons nationales; et partour éclataient la même énergie et la même vie rythmiques: c'étais un enchantement. On ne pouvait se défendre d'envier les députés aux Cortès, en l'honneur de qui cette musique était improvisée: la politique, en France, n’a pas de telles récréations.

Ce souvenir, demeuré présent, devait attirer particulièrement mon intérêt sur l'Orfeó Català, qui la semaine dernière s'est fait entendre à Paris por la première fois. Cet Orfeó est le plus célèbre choeur de la Catalogne; il ne se compose pas d'hommes seulement, comme celui de Gérone, mais des voix de femmes et d'enfents s'y mêlent aux voix masculines. Fondé à Barcelone, il y a quelque vingt-cinq ans, par M. Lluis Millet, qui le dirige encore aujourd'hui, il n'a cessé de se développer sous l'action persévérante et passionnée de son chef, et il a conquis dans toute l'Espagne une renommée sans égale. Les deux concerts qu'il vient de donner au théâtre des Champs-Elysées et au Trocadéro ont prouvé que cette réputation est pleinement justifiée. L'Orfeó Català est sans contredit une des meilleures associations chorales qui soient au monde: il possède à l'état de perfection les plus rares qualités d'exécution et de virtuosité. Sa justesse d'intonation est absolue et sans défaillance : il chante des morceaux a capella d'une longueur et d'une difficulté exceptionnelles, tels que l'Hymne à seize parties de M. Richard Strauss, ou bien que le «Credo» de la Messe du pape Marcel, sans qu'à la fin les voix aient baissée du plus imperceptible intervale: l'épreuve du diapason démontrerait qu'elles n'ont point «bougé». L'Orfeó Català unit l'extreme délicatesse: dans la conclusion du «Credo» de Palestrina, l'ampleur, la plénitude, le volumen de la sonorité étaient magnifiques; et dans maints passages des autres oeuvres interprétées, cette puissante masse chorale atteignait à l'extrême ténuité et à l'extrême délicatesse: on ne peut user des nuances avec plus d'aisance et de souplesse, et un art plus consommé. Les attaques ont une franchise et un ensemble superbes: la mesure et le rythme sont irréprochablement exacts, précis et nets. C'est en vérité un choeur presque incomparable: du moins ne pouvons-nous lui comparer aucun des choeurs qui existent chez nous; Paris n'a jamais eu une société chorale qui rivalise avec cette société-là; et sans doute il n'en aura jamais ${ }^{34}$.

34. Le Temps, 23 junio de 1914, p. 3. 
VIRGINIA SÁNCHEZ RODRÍGUEZ

EL ORFEÓ CATALÀ Y SUS CONCIERTOS PARISINOS DE 1914: DE LA ESTELA

DE UNA DIVA AL TRIUNFO DE LO POPULAR

Sin embargo, el crítico de Le Temps, además de deshacerse en elogios por la técnica de la agrupación catalana, los cuales continúa posteriormente en su crónica, también realiza una reflexión en torno al repertorio seleccionado. Por un lado, Pierre Lalo señala la perfección interpretativa de la obra de Victoria interpretada en ambos conciertos, aludiendo al espíritu de la «raza» española de los intérpretes ante la creación de un compatriota. Por otro lado, Lalo señala la trascendencia patrimonial de algunas de las composiciones del programa, pero también alude al menor valor de las obras de carácter popular, tanto en lo relativo a la «mediocridad de los arreglos de temas populares» como en lo referente a las menores posibilidades interpretativas de este tipo de cantos, destacando como excepción la canción de Pedrell titulada «Don Juan i don Ramon» por su calidad compositiva «profundamente inspirada por el estilo coral de los maestros del Renacimiento». En todo caso, al final de sus referencias a la agrupación española, el crítico reitera la excelencia técnica del Orfeó y lo anima a recuperar las obras de los grandes polifonistas españoles:

L'exécution de l'Orfeó Català mérite donc les plus grands éloges; l'interprétation, et aussi la composition des programmes, en méritent un peu moins. Trop de morceaux, dans ces programmes, sont ou bien de médiocres arrangements de thèmes populaires, eux-mêmes choisis sans goût et souvent insignifiants, ou bien des compositions descriptives et sentimentales, pleines d'oppositions artificielles, d'effets de voix, d'imitations de bruits divers, sons de cloches ou roulements de tambour: véritable musique d'orphéon, digne peut-être d'un orphéon ordinaire, peu digne d'un choeur tel que l'Orfeó Català. (Parmi ces faibles compositions, il faut réserves une place à part à un ouvrage de Pedrell, intitulé «Don Juan i don Ramon», quie est d'une qualité musicale beaucoup plus relevée, et dont le style chorale est profondément inspiré des maitres de la Renaissance). De ces maîtres admirables, on nous a bien fait entendre quelques oeuvres, mais en trop petit nombre; et c'est dans ces oeuvres surtout, à une exception près, que se sont révélés les défauts de l'interprétation. Ces défauts se résument en un seul: la recherche de l'effet; de tous les effets, effets vocaux, effets de contrastes dans les nuances et dans les mouvements; pianissimos exagérés, ralentissement superflus, excès d'agrément, de suavité et de finesse. Ce sont d'ailleurs là des défauts presque obligés, et vers lesquels une association chorale pourvue de talents exceptionnels se trouve entrâinée comme par une inclination fatale. Plus elle est capable dans son exécution de trouver le fini, le poli, le joli, et plus elle les cherche, et plus elle a de penchant à les chercher avant toute chose; le succès qu'elle obtient l'y sollicite encore davantage. Il faudrait pour l'en préserver ce mâle sentiment de la musique qui est celui de certaings choeurs septentrionaux, comme les Suédois et les Norvégiens, ou bien la communion encore immédiate avec l'âme populaire qui faisait l'attrait du choeur entendu dans la rue de Gérone. L'Orfeó Català est devenu un choeur fort civilisé, en possession d'une technique et d'une virtuosité extraordinaires; il est porté à abuser de cette technique et de cette virtuosité, et par endroits à les préférer inconsciemment à la musique elle-même. C'est ainsi que le «Credo» de la Messe du pape Marcel, composition d'une admirable unité, où les idées se développent avec une si magnifique et si sereine ordonnance, 
a été découpé en une quantité de petits fragments, violemment contrastés par des changements subits de mouvements, des oppositions imprévues de nuances: la suite de la pensée disparaissait; l'ampleur du sentiment était détruite: on ne peut rien concevoir de moins palestrinien, ni de moins romain. Le «Chant des oiseaux», de Clément Jannequin, n'a pas eu non plus, dans les charmants couplets lyriques qui relient les diverses imitations du caquet des chanteurs ailés, le caractère de vieille chanson française qui lui convient; ni la cantate de Bach «Singet dem Herrn ein neues Lied», la forte sobriété qu'il faut lui savoir donner. En revanche, le motet de Victoria, "O magnun mysterium», qui est une des oeuvres les plus sublimes de la musique de la Renaissance, a été chanté de façon digne de luis, avec une unité, une simplicité, une gravité, une profondeur sans pareilles: ce furent les plus précieuses minutes de ces deux concerts, et véritabement des minutes admirables. Puisque l'Orfeó Català s'est montré capable, dans cette occasions particulière, d'une interprétation si belle, porquoi n'en est-il pas capable toujours ? Serait-ce que Victoria était Espagnol, et que le sens de la race inspire ici les chanteurs catalans, tandis qu'il ne les inspire pas dans les oeuvres allemandes, ou françaises, ou romaines ? Il se peut. Je serais d'ailleur désolé de vous voir attacher trop d'importance aux réserves que j'ai faites sur l'interprétation de l'Orfeó Català: malgré ces erreurs légères, on prend à l'entendre un plaisir extrême. Mais si, comme je l'espère, il revient nous rendre visite, qu'il chante moins d'arrangements pseudo-populaires, moins de morceaux à effet; et qu'il donne plus de place aux chefs-d'oeuvre d'un Victoria, d'un Guerrero, d'un Morales: ces maîtres, qui furent jadis l'honneur de la musique espagnole, font encore aujourd'hui sa richesse et sa gloire ${ }^{35}$.

Lo cierto es que la crítica de Le Temps indica que el propósito del periplo a París y Londres se había cumplido en su primer destino: además de mostrar la calidad interpretativa del Orfeó Català en la capital de Francia, otro de los motivos del viaje - según consta en la introducción del libreto de viaje escrita por Millet, a la que aludimos previamente - era divulgar la excelencia de la cultura musical catalana a través de sus componentes, cuyas voces eran capaces de dar vida y difundir las virtudes de Cataluña a través de una selección de canciones populares, más allá de la calidad compositiva de las mismas.

Por su parte, los medios españoles, al igual que sucedió tras la primera actuación en suelo francés, también se hicieron eco de la exitosa interpretación de la agrupación barcelonesa en su segunda aparición. Véase al respecto, entre otros, la portada del Heraldo de Madrid, con fecha de 17 de junio de 1914:

Se ha celebrado esta noche el último concierto dado por el Orfeó Catalá, verificándose el acto en la gran sala de fiestas del Trocadero y asistiendo al mismo compacta concurrencia, entre la que figuraban muchas personalidades españolas y francesas.

35. Ibid., p. 3. 
VIRGINIA SÁNCHEZ RODRÍGUEZ

EL ORFEÓ CATALÀ Y SUS CONCIERTOS PARISINOS DE 1914: DE LA ESTELA

DE UNA DIVA AL TRIUNFO DE LO POPULAR

Al presentarse los ejecutantes, estalló una ruidosa ovación, la que se redobló al entonar el orfeón su himno, seguido de canciones populares, que entusiasmaron a los concurrentes, demostrándolo estos al despedir con atronadores aplausos a la Sociedad coral ${ }^{36}$.

El diario $A B C$ también recogió el éxito tras la segunda actuación, aunque, en la línea de las anteriores reseñas, las referencias fueron escuetas. Aún así, no faltaron las alabanzas para la labor del Orfeó Català y la referencia a la calurosa aclamación por parte del público ante tal magistral interpretación:

El segundo y último concierto del Orfeó Català, celebrado en la gran sala de fiestas del Trocadero, ha obtenido un éxito superior al primero.

La concurrencia, compuesta de más de 7.000 personas, ovacionó a los ejecutantes.

La colonia española estuvo brillantemente representada.

Concurrió también la alta sociedad parisiense y un grupo de eminentes personalidades artísticas.

El Orfeó tuvo que repetir casi todos los números de su programa.

Al concluir el concierto, el público aclamó a los ejecutantes ${ }^{37}$.

De la prensa española, La Vanguardia continuó siendo el medio que ofreció mayor detalle, pues recordemos que José Escofet acompañó a la agrupación durante todo el periplo, también posteriormente en su visita a la ciudad de Londres. El éxito del segundo concierto parisino se destaca, igualmente, con gran detalle en la crítica publicada el 17 de junio de 1914:

\section{El segundo concierto. Otro éxito.}

El segundo y último concierto dado por el Orfeó Cátala en la grandiosa sala del Trocadero ha sido un nuevo triunfo que ha sobrepujado á cuanto pudiera esperarse, entusiasmándose el público, a pesar de las malas condiciones acústicas del local. Se ha registrado un lleno completo, calculándose en unas tres mil personas el número de oyentes, entre los cuales figuraba la colonia española, que ha respondido admirablemente, y escogida sociedad parisién, presentando la sala un brillante aspecto. El maestro Millet ha sido aclamado. Se han cantado la «Canga de Nadal», «La Gata y en Belitre», «Montanyas del Canigó», «Cançó del breçol», «La Mare de Deu», y otras, repitiéndose la penúltima ante los estruendosos e insistentes aplausos con que lo pedía el público.

Al final del concierto fueron los ejecutantes objeto de una larga y calurosa ovación. El éxito obtenido por el Orfeó en este segundo concierto ha sido grandioso, definitivo, pues los calurosos aplausos y delirantes ovaciones con que se ha premiado su trabajo son la sanción de un público inteligente y escogido, entre el cual figuraban

36. Heraldo de Madrid, 17 de junio de 1914, p. 1.

37. $A B C, 17$ de junio de 1914, p. 15. 
VIRGINIA SÁNCHEZ RODRÍGUEZ

EL ORFEÓ CATALÀ Y SUS CONCIERTOS PARISINOS DE 1914: DE LA ESTELA

DE UNA DIVA AL TRIUNFO DE LO POPULAR

los más distinguidos aficionados, gran número de artistas y los críticos musicales de los más importantes diarios y revistas musicales de París, que habían acudido a este concierto atraídos por haberse esparcido rápidamente la fama artística de la masa coral barcelonesa y la inmejorable impresión que dejara el «Orfeón entre los que asistieron al primer concierto.

La «cobla» de Peralada.

La «Cobla La Principal», de Peralada, que ha venido para tomar parte en el segundo concierto, en sustitución del número que no pudo ponerse por hallarse indispuesta la triple señora Barrientes, ha ejecutado una sardana de Pujol y otra de Manen, gustando mucho y siendo muy aplaudida con entusiasmo, aunque no fueron los aplausos tan intensos como los que se tributaron al Orfeó. De todos modos, ha tenido un gran éxito la «cobla» de Peralada, y puede envanecerse de él.

\section{Probables condecoraciones.}

Es probable que el Presidente de la República, M. Poincaré, imitando lo hecho en casos análogos por el Rey de España, conceda las palmas académicas al director del Orfeó, señor Millet, y al presidente, señor Mateu ${ }^{38}$.

Junto con las alabanzas a la agrupación, cabe señalar que, tras la actuación, los medios franceses no ofrecieron detalles sobre la indisposición de María Barrientos y su ausencia en el programa previsto, sino que, por el contrario, se dedicaron a alabar el buen hacer de Lluís Millet, de los componentes de la agrupación y de los instrumentistas participantes en uno y otro concierto. Por su parte, la prensa española, que siguió con mucho interés el periplo del Orfeó junto a su soprano más célebre, no solo se hizo eco del éxito de las actuaciones de la agrupación, sino también del malestar que impidió la presencia de la Barrientos, atribuida por parte de la prensa patria a un atragantamiento con una cáscara de huevo. En relación con la excelencia musical del Orfeó y la indisposición de la diva, véase al respecto un extracto de la crónica publicada por Escofet en La Vanguardia, con fecha de 18 de junio de 1914.

Por un momento se había temido un fracaso. Gran parte del éxito se fiaba a María Barrientos, nuestra artista eminente. Pero María Barrientos no pudo cantar, diz que por habérsele atravesado una cascarilla de huevo en la garganta. La diva tiene la costumbre de tomarse un par de huevos pasados por agua todos los días, y se pasó, junto con las yemas, un pedacito de cáscara que despertó inquietud profunda en el Orfeó.

Por el canto de una cáscara de huevo se perdió el canto angélico de María y nos sentimos todos desencantados. Pero fue un momento; el Orfeó no podía detenerse por una cáscara y se presentó solo. Y fue aclamado, fue vitoreado, fue glorificado.

38. La Vanguardia, 17 de junio de 1914, p. 14. 
VIRGINIA SÁNCHEZ RODRÍGUEZ

EL ORFEÓ CATALÀ Y SUS CONCIERTOS PARISINOS DE 1914: DE LA ESTELA

DE UNA DIVA AL TRIUNFO DE LO POPULAR

El maestro Millet tuvo ante sí, de pie, a todo el público elegante de París, que le rendía homenaje de admiración y simpatía. Todo ello sin Barrientos y sin prensa; pero con una masa coral incomparable y con el talento y la voluntad que le han servido al maestro para formar el Orfeó y dar gloria a Cataluña.

(...)

Y a propósito de malas interpretaciones: no se tome por los cabellos lo ocurrido entre María Barrientos y el Orfeó Català. Nuestra gran cantante estuvo de veras enferma y es exacto lo de la cáscara de huevo. No hablábamos en broma.

No hay quien pueda discutirle a María Barrientos que vino de Nueva York expresamente para cantar con el Orfeó. Como quiera que el incidente habrá de provocar algunos comentarios, adelantamos el nuevo, evitando de este modo que sean los otros torcidos y maliciosos. María Barrientos estaba dispuesta a cantar cuando llegó el Orfeó a París; pues, por lo visto, el percance de la cáscara no fue cosa mayor; pero se había despedido ya a la orquesta y estaba también modificado el programa. Todos nos alegramos de que el Orfeó haya triunfado sin la colaboración de la diva; pero es porque de este modo su triunfo es más significativo y propio. No hay para María Barrientos ninguna humillación, ningún perjuicio. Cantará con el Orfeó en Londres y la aplaudiremos todos, sintiendo siempre que un indiscreto y pérfido pedacito de cáscara de huevo nos privara en París de sus arpegios y de sus trinos. En cambio nos proporcionó la satisfacción de ver que el Orfeó Català triunfaba por sí solo, y esto si acaso le doliera a María en su susceptibilidad de artista, ha de alegrarla en su corazón de patriota; de suerte que no vino del todo mal la cascarilla ${ }^{39}$.

Tal como señala Escofet en el artículo, la indisposición de Barrientos no significó un fracaso sino un éxito en solitario para la sociedad coral. Además, cabe decir que, finalmente, el programa musical de las actuaciones resultó todo un tributo a la cultura popular catalana debido al elevado porcentaje de canciones de tintes folklóricos, especialmente en el segundo recital a través de la presencia de la Cobla de Peralada como sustituto de la Barrientos. Esa circunstancia hizo las delicias de la crítica, donde también se incide en el buen hacer del Orfeó ante piezas del repertorio culto de carácter universal.

Tras el reconocimiento en la capital francesa, y ya con la Barrientos recuperada, los componentes del Orfeó, el resto de artistas catalanes y la comitiva se dispusieron a seguir su gira hasta suelo británico. Todos ellos salieron desde París el día 17 de junio, desde la Estación del Norte, hasta Calais, donde tomaron un barco, atravesaron el Canal de la Mancha hasta su llegada a Douvres y, posteriormente, continuaron en tren hasta Londres. En la capital británica continuaron los éxitos que había rodeado a la agrupación en París, una aventura en la que profundizaremos en otra ocasión y donde triunfaron, a partes iguales, María Barrientos y el Orfeó Català.

39. La Vanguardia, 18 de junio de 1914, pp. 10-11. 
VIRGINIA SÁNCHEZ RODRÍGUEZ

EL ORFEÓ CATALÀ Y SUS CONCIERTOS PARISINOS DE 1914: DE LA ESTELA

DE UNA DIVA AL TRIUNFO DE LO POPULAR

\section{CONCLUSIONES}

Tras lo expuesto previamente, en primer lugar, podemos afirmar que la presencia del Orfeó Català en la programación cultural de París fue todo un éxito, lo que significó todo un orgullo para Lluís Millet, para los altos cargos de la institución y para los propios componentes. Por un lado, se logró cumplir con el principal objetivo de esta gira consistente en difundir la música de Cataluña en Europa, "proclamar en el gran mundo civilizado nuestra cultura artística», según las palabras de Millet en la presentación del libreto a los orfeonistas. Efectivamente, los dos conciertos ofrecidos en la capital de Francia dotaron de un gran protagonismo a la cultura popular, fruto de la convivencia de obras de grandes polifonistas y de armonizaciones sobre canciones tradicionales catalanas.

Por otro lado, cabe decir que la recepción por parte del público y de la prensa fue absolutamente positiva ante el buen hacer del Orfeó en sus dos actuaciones parisinas. La prensa francesa se deshizo en halagos, refiriéndose a la agrupación dirigida por Millet como la institución más relevante en su género por encima de otros países con mayor tradición coral, y destacó la calidad técnica del conjunto y la pertinencia del repertorio. Cabe decir que todas las críticas francesas coinciden en evidenciar la perfección técnica de los aficionados que forman parte del Orfeó, incluso en grandes obras de la historia de la música de elevada dificultad, y en señalar el agradable colorido y el exotismo de las obras de perfil popular. A este respecto, Pierre Lalo, en su crítica para Le Temps tras ambos conciertos, coincide con los aspectos referidos, pero también señala el escaso valor propiamente musical de las armonizaciones de algunas de las canciones interpretadas, lo que podría deslucir la calidad vocal de la agrupación. Sin embargo, cabe reiterar que la calidad de dichos arreglos corales no era una de las principales preocupaciones de Millet en la selección del repertorio para su viaje a París y Londres, pues su propósito primordial, recordemos, era utilizar las voces del Orfeó, en su perfección interpretativa, como un instrumento para difundir las virtudes de Cataluña a través de algunas de las canciones populares más representativas de la región.

Por su parte, los medios españoles también se enorgullecieron de la buena acogida de la institución coral. Aunque, en general, la prensa de carácter nacional recogió varias reseñas de los dos conciertos ofrecidos en París, La Vanguardia fue aquel que dedicó un mayor espacio y detalle a la actuación de la agrupación de su ciudad gracias a las críticas de José Escofet. Más allá de los tintes evidentemente nacionalistas, en relación con el carácter artístico de las actuaciones, Escofet da cuenta del gran éxito de la agrupación en ambos conciertos y también menciona oportunamente a las personalidades francesas que asistieron a los eventos, a modo de argumento de autoridad. Cabe señalar que esta mención resulta muy oportuna y significativa puesto que demuestra que Fauré, Dukas, Debussy y Ravel tuvieron la oportunidad de disfrutar del primer concierto en París del Orfeó. Recordemos 
que todos estos compositores, a lo largo de su vida, mostraron admiración por la cultura española, hasta el punto de introducir evocaciones a España en algunas de sus obras.

En otro orden, cabe señalar que, en un primer momento, el nombre del Orfeó Català iba asociado al de la cantante María Barrientos a modo de reclamo publicitario en la capital francesa, donde ésta ya era considerada una celebridad por su labor como soprano de coloratura en varias óperas en la ciudad y por su carrera internacional previa. Esa circunstancia explica que el nombre de la Barrientos apareciera con un gran tamaño en los programas de ambos conciertos. Sin embargo, debido a un accidente - que la prensa francesa no detalla pero que, según la prensa española, se debió a un atragantamiento-, la diva no pudo llevar a cabo las interpretaciones previstas. Ante esta circunstancia, cabe decir que la ausencia de María Barrientos no empañó ninguno de los dos conciertos; por el contrario, el Orfeó brilló con luz propia.

En ese sentido, la ausencia de la diva dio como resultado una mayor incidencia del repertorio popular: mientras que el programa del primer concierto - ofrecido el 14 de junio en el théâtre des Champs-Elysées - pudo mantenerse, en el caso de la segunda actuación - con fecha de 16 de junio en el théâtre de Trocadéro-, y debido a la imposibilidad de que la Barrientos interpretara la Oda Ceciliana de Haendel, se optó por contar con la presencia de la cobla Peralada, que interpretó varias danzas populares eminentemente instrumentales. Este cambio en el programa añadió mayores tintes exóticos y populares al evento, logrando una muy buena acogida por parte del público y de la prensa.

Quizá hoy en día, en la época actual, podría sorprender que la selección de un repertorio localista contara con una acogida de tales magnitudes en el extranjero, pero a comienzos del siglo XX, entroncando con el sentimiento nacionalista y con el exotismo y las evocaciones generadas desde el exterior, resultó ser la tónica dominante. Esa circunstancia coincide también con el interés por lo popular presentado por los artistas de élite dedicados, principalmente, a la música de concierto. En el caso de la gira del Orfeó Català por París y Londres, esa circunstancia la representan Barrientos, pero también Manén y Blai, todos ellos músicos de primer nivel, lo que demuestra la versatilidad de estos artistas y la estrecha línea entre lo culto y lo tradicional, especialmente si existen nexos de un mismo sentimiento local, como era el caso de todos ellos.

En todo caso, resulta evidente que la dualidad entre lo popular y lo culto en las actuaciones del Orfeó Català de París fue algo premeditado. Tras lo expuesto en este trabajo, podemos afirmar que el buen hacer de los orfeonistas, dirigidos por Millet, dio como resultado un baño de merecido reconocimiento a la calidad técnica de esta agrupación musical, todo ello en dos actuaciones que se convirtieron en una fiesta del folklore catalán en la capital de Francia a través de un programa 
VIRGINIA SÁNCHEZ RODRÍGUEZ

EL ORFEÓ CATALÀ Y SUS CONCIERTOS PARISINOS DE 1914: DE LA ESTELA

DE UNA DIVA AL TRIUNFO DE LO POPULAR

igualmente bien ejecutado en lo relativo a las grandes obras polifónicas y a las canciones populares catalanas seleccionadas.

\section{REFERENCIAS BIBLIOGRÁFICAS}

Bonastre, Francesc (1991-1992). «El nacionalisme musical de Felip Pedrell. Reflexions a l'entorn de Por nuestra música...», Recerca Musicològica, XI-XII, pp. 17-26.

Casares, Emilio (1991-1992). «Pedrell, Barbieri y la restauración musical española», Recerca Musciològica, XI-XII, pp. 259-271.

Gregori, Josep Maria (1991-1992). «Felip Pedrell i el renaixement musical hispànic», Recerca Musicològica, XI-XII, pp. 47-61.

Millet i Loras, Lluís (2004-2005). «El llegat històric de l'Orfeó Català (1891-1936)», Recerca Musicològica, XIV-XV, pp. 139-153.

Millet i Loras, M. Dolors (1986-1987). «Lluís Millet a Felipe Pedrell -Epistolari-», Recerca Musicològica, VI-VII, pp. 261-342).

Narváez Ferri, Manuela (2005). L'Orfeó Català, cant coral i catalanisme (1891-1951) (tesis doctoral), Barcelona: Universitat de Barcelona.

Orfeó Català (1914). Orfeó Català. Excursió artística a París i a Londres, Barcelona: Henrich y Comp.

Roig Rosich, Josep Maria (1993). L’Orfeó Català. Moments cabdals del seu passat, Barcelona: Publicacions de l'Abadia de Montserrat.

Romeo Mateo, María Cruz; Saz, Ismael (coords.) (2002). El siglo XX. Historiografía e historia. Valencia: Universitat de València.

Sánchez Rodríguez, Virginia (2014). «La dignificación de lo popular en la música renacentista», ArtyHum: revista digital de artes y bumanidades, 3, pp. 119-211. Disponible en: <https://www.artyhum.com/> [Última consulta: 11 de junio de 2018].

Sánchez Rodríguez, Virginia (2017). «Nacionalismo y universalismo en torno al pensamiento musical de Manuel de Falla», ArtyHum: revista digital de artes y humanidades, 38, pp. 122-141. Disponible en: <https://www.artyhum.com/> [Última consulta: 11 de junio de 2018].

Sánchez Rodríguez, Virginia (2018). La soprano María Barrientos y sus epistolas de juventud, Málaga: Universidad de Málaga.

\section{FUENTES HEMEROGRÁFICAS}

$A B C, 14$ de junio de 1914 .

$A B C, 15$ de junio de 1914 .

$A B C, 17$ de junio de 1914 .

$A B C, 18$ de junio de 1914 .

Bulletin Municipal Officiel de la Ville de Paris, año XXXIII, nº 170, pp. 2515-2518.

El Correo Español, 15 de junio de 1914. 
VIRGINIA SÁNCHEZ RODRÍGUEZ

EL ORFEÓ CATALÀ Y SUS CONCIERTOS PARISINOS DE 1914: DE LA ESTELA

DE UNA DIVA AL TRIUNFO DE LO POPULAR

El Correo Español, 17 de junio de 1914.

El Globo, 15 de junio de 1914.

El imparcial, 15 de junio de 1914.

Gil Blas, 17 de junio de 1914.

Heraldo de Madrid, 17 de junio de 1914.

L'Aurore: littéraire, artistique, sociale, no 6035, 12 de junio de 1914.

La Correspondencia, 15 de junio de 1914.

La época, 15 de junio de 1914.

La Lanterne: journal politique quotidien, 8 de junio de 1914.

La Vanguardia, 15 de junio de 1914.

La Vanguardia, 16 de junio de 1914.

La Vanguardia, 17 de junio de 1914.

La Vanguardia, 18 de junio de 1914.

Le Figaro, 16 de junio de 1914.

Le Figaro, 18 de junio de 1914.

Le Temps, 23 junio de 1914.

Le Temps, 23 junio de 1914.

Le XIXe siècle: journal quotidien politique et littéraire, n 16193, 15 de junio de 1914.

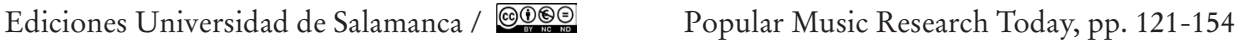

